\title{
Composição Química de Forrageiras e Seletividade de Bovinos em Bosque-de-Sabiá (Mimosa caesalpiniifolia Benth.) nos Períodos Chuvoso e Seco ${ }^{1}$
}

\author{
Ednéia de Lucena Vieira ${ }^{2}$, Francisco F. Ramos de Carvalho ${ }^{3}$, Ângela Maria Vieira Batista ${ }^{3}$, \\ Rinaldo Luiz C. Ferreira ${ }^{4}$, Mércia Virgínia Ferreira dos Santos ${ }^{3}$, Mário de Andrade Lira ${ }^{5}$, Maria \\ José da Silva ${ }^{6}$, Edna Maria Bonfim da Silva ${ }^{7}$
}

\begin{abstract}
RESUMO - A pesquisa foi desenvolvida no período de junho de 1999 a março de 2000, com o objetivo de determinar, nos períodos chuvoso e seco, a composição química de sabiá (Mimosa caesalpiniifolia Benth.), com acúleo e sem acúleo, na dieta de bovinos em condições de pastejo e a composição botânica do bosque de sabiá e da dieta selecionada. Não foi observada diferença significativa quanto à composição química entre os sabiás com e sem acúleo, obtendo-se valores médios, no período chuvoso, de 26,45\% de matéria seca (MS), 27,63\% de proteína bruta (PB), 44,39\% de fibra em detergente neutro (FDN), 25,80\% de fibra em detergente ácido (FDA), 1,24\% de cálcio (Ca), 0,22\% de fósforo (P), 1,63\% de potássio (K) e 1,12\% de sódio (Na). No período seco, os valores médios observados foram de 42,39\% de MS; 19,30\% de PB; 39,05\% de FDN; 21,83\% de FDA; 1,25\% de Ca; 0,15\% de P; 1,63\% de K e 0,27\% de Na. Para a composição botânica da dieta, observou-se que, durante o período chuvoso, as amostras de extrusa apresentaram maior participação de sabiá $(83,1 \%)$ que no período seco (12,3\%). Os resultados obtidos indicaram que, durante o período chuvoso, os animais selecionaram sabiá em maior quantidade para sua dieta e que a coleta manual, como realizada, superestimou a fração fibrosa da dieta calculada a partir da composição química da extrusa.
\end{abstract}

Palavras-chave: forrageira nativa, semi-árido, proteína, extrusa

\section{Chemical Composition of Forage and Selectivity by Bovines of "Sabiá" (Mimosa caesalpiniaefolia Benth.) in the Rainy and Dry Seasons}

\begin{abstract}
This trial was carried out from June 1999 to March 2000 to evaluate the chemical composition of samples of sabiá legume (Mimosa caesalpiniaefolia Benth.), with and without thorns, collected in the rainy and dry seasons and to compare the botanical composition of sabiá pasture with that of the diet selected by the grazing animals. No significant difference was observed in chemical composition between samples of sabiá with and without thorns. The mean values obtained in the rainy samples were: $26.45 \%$ drymatter (DM), 27.63\% crude protein (CP), 44.39\% neutral detergent fiber (NDF), 25.80\% acid detergent fiber (ADF), 1.24\% calcium (Ca), $0.22 \%$ phosphorus $(\mathrm{P}), 1.63 \%$ potassium $(\mathrm{K})$ and $1.12 \%$ sodium $(\mathrm{Na})$. In the dry period samples, the mean values observed were: 42.39\% DM, 19.30\% CP, 39.05\% NDF, 21.83\% ADF, 1.25\% Ca, 0.15\% P, 1.63\% K and 0.27\% Na. Considering the botanical composition, the rainy extrusa sample showed higher participation of sabiá (83.1\%) as compared to the dry period (12.3\%). During the rainy period, the animals selected sabiá in higher quantity while the hand plucked samples overestimated the dietary fiber fraction as compared to values for the extrusa samples.
\end{abstract}

Key Words: native forage, legume, semi arid, protein, neutral detergent fiber, extrusa

\section{Introdução}

O Nordeste brasileiro é uma região caracterizada por índices pluviométricos irregulares, com períodos de estiagem prolongados e má distribuição de chuvas. Como conseqüência, a produtividade dos rebanhos manejados em regime de pastejo é comprometida principalmente pela limitação das fontes protéicas e energéticas disponíveis, o que exige suplementação alimentar, elevando consideravelmente os custos de produção. A suplementação alimentar dos rebanhos nordestinos deve ser voltada para alternativas que diminuam os custos de produção, como o cultivo de plantas forrageiras de reconhecido valor nutritivo. O fornecimento de forrageiras existentes na região, nas formas verde, fenada ou ensilada, pode suprir, em boa parte, a deficiência das pastagens nos períodos de estiagem a custos relativamente baixos.

\footnotetext{
${ }^{1}$ Parte da Dissertação apresentada à UFRPE e trabalho realizado pelo acordo IPA/UFRPE e financiado pela FACEPE.

${ }^{2}$ Aluna do Programa Integrado de Doutorado em Zootecnia da Universidade Federal Rural de Pernambuco (UFRPE) (edneiavieira@ig.com.br). 3 Professor do Departamento de Zootecnia da UFRPE, bolsista do CNPq (ffrcarva@ufrpe.br; abatista@ufrpe.br; mercia@ufrpe.br).

${ }^{4}$ Professor do Departamento de Ciência Florestal da UFRPE, bolsista do CNPq (rinaldof@ufrpe.br).

5 Pesquisador da Empresa Pernambucana de Pesquisa Agropecuária (IPA), Bolsista CNPq (mlira@ipa.br).

${ }^{6}$ Zootecnista do Departamento de Zootecnia da UFRPE.

7 Aluna do Programa de Doutorado em Solos da ESALQ (embonfim@esalq.usp.br).
} 
Entre as diversas formas de se reduzir ou minimizar o problema da escassez de forragem durante o período seco, destaca-se a utilização de espécies forrageiras leguminosas forrageiras arbustiva-arbóreas existente na região. O sabiá (Mimosa caesalpiniiifolia Benth.) é uma leguminosa comum em alguns sítios ecológicos do Nordeste muito consumida pelos animais no período chuvoso, sendo utilizada também como suplemento alimentar nos períodos de escassez, quando fenada. Essa forrageira arbórea pode atingir até $7 \mathrm{~m}$ de altura e apresenta caule com presença ou ausência de acúleos; seus ramos são de alta palatabilidade e contém, em média, 17\% de proteína bruta (Barbosa 1997).

O sabiá, por ser bem aceito pelos animais, pode apresentar limitações no uso como forrageira, tendo em vista a ocorrência predominante de ramos com acúleos, que dificultam o manejo e a utilização da planta (Silva et al., 1984). Segundo Carvalho et al. (1990), a ausência de acúleos é recomendável para o emprego do sabiá como forrageira, favorecendo a melhor circulação de animais, máquinas e equipamentos nos piquetes. Portanto, é importante o conhecimento da preferência dos animais para que se possa implantar manejo adequado às pastagens, com a finalidade de se manter as espécies forrageiras mais selecionadas e consumidas pelos animais.

Objetivou-se determinar, nos períodos chuvoso e seco, a composição química de sabiá (Mimosa caesalpiniifolia Benth.), com acúleo e sem acúleo, na dieta de bovinos em condições de pastejo e determinar as composições botânica e química das espécies forrageiras presentes na extrusa.

\section{Material e Métodos}

O experimento foi realizado na Estação Experimental de Itambé, pertencente à Empresa Pernambucana de Pesquisa Agropecuária-IPA, situada no município de Itambé-PE, situado a $92 \mathrm{~km}$ de Recife. A precipitação pluviométrica do município de Itambé-PE durante o período experimental é apresentada na Figura 1.

Segundo Jacomine (1972), os solos da região onde está localizada a Estação Experimental de Itambé são classificados como Podzólico Vermelho-Amarelo equivalente eutrófico, textura argilosa, fase floresta subcaducifólia e relevo ondulado. As amostras de solo da área experimental apresentaram a seguinte composição: $\mathrm{pH}=5,45 ; \mathrm{P}=5,14 \mathrm{mg} \cdot \mathrm{dm}^{-3} ; \mathrm{K}=$

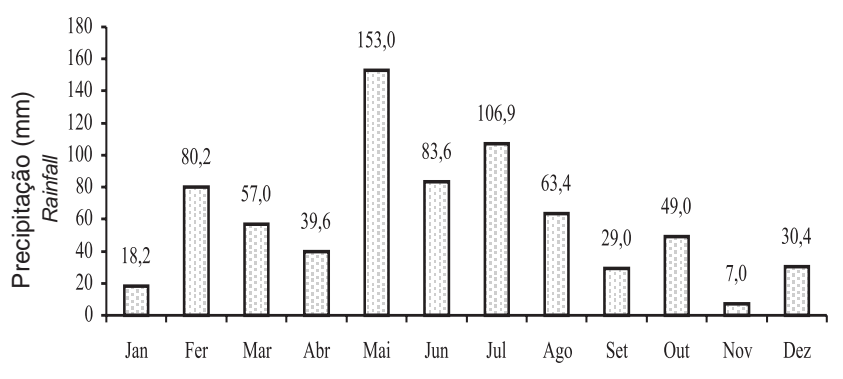

Figura 1 - Precipitação pluviométrica do município de Itambé-PE no ano de 1999.

Figure 1 - Pluvial precipitation of the county Itambé-PE in the year of 1999.

$0,2 \mathrm{cmol}_{\mathrm{C}} \cdot \mathrm{dm}^{-3} ; \mathrm{Ca}=3,1 \mathrm{cmol}_{\mathrm{C}} \cdot \mathrm{dm}^{-3}$; e $\mathrm{Mg}=$ $0,52 \mathrm{cmol}_{\mathrm{C}} \cdot \mathrm{dm}^{-3}$.

Como área de pastejo, utilizou-se um bosque-desabiá com aproximadamente oito anos de idade, constituído de 225 plantas obtidas por semente (109 com acúleos e 116 sem acúleos). A vegetação próxima à área de plantio de sabiá era constituída de capimbraquiária (Brachiaria decumbens Stapf.), que, ao longo do tempo, passou a ocupar as margens do bosque, representando aproximadamente $20 \%$ da área total.

As coletas foram realizadas nos meses de junho e julho (período chuvoso) e outubro e novembro (período seco) de 1999, sempre na segunda semana de cada mês. O sabiá foi coletado retirando-se a folha e o pecíolo, por tração manual, em diversas partes da planta à altura do alcance dos animais, ou seja, a 1,60 m de altura. O capim-braquiária foi coletado a $10 \mathrm{~cm}$ do solo. Após a colheita, o material foi submetido à pesagem e colocado em estufa de circulação forçada a $55^{\circ} \mathrm{C}$, por 72 horas. Em seguida, foi triturado em moinho com peneira de $1 \mathrm{~mm}$, para determinação dos teores de matéria seca (MS), proteína bruta $(\mathrm{PB})$, extrato etéreo ( $\mathrm{EE})$, fibra em detergente neutro (FDN), fibra em detergente ácido (FDA), energia bruta (EB), matéria mineral (MM), lignina (LIG), celulose (CEL) e nitrogênio (N), conforme metodologia descrita por Silva \& Queiroz (2002). O nitrogênio insolúvel em detergente ácido (NIDA) foi determinado no resíduo da determinação da FDA. Os níveis dos minerais cálcio (Ca), fósforo $(\mathrm{P})$, potássio $(\mathrm{K})$, sódio $(\mathrm{Na})$, magnésio $(\mathrm{Mg})$, enxofre $(\mathrm{S})$, ferro $(\mathrm{Fe})$, cobre $(\mathrm{Cu})$, zinco $(\mathrm{Zn})$ e manganês (Mn) foram determinados segundo metodologia descrita por Malavolta et al. (1989) e Bezerra Neto et al. (1994). 
Foram utilizados quatro bovinos girolandos machos, inteiros, com média de 18 meses de idade e peso vivo médio inicial de $246 \mathrm{~kg}$, fistulados no esôfago, conforme técnica descrita por Bishop \& Froseth (1970). Durante os períodos experimentais, mensalmente (junho, julho, outubro e novembro), os animais tinham acesso ao bosque-de-sabiá, por dez dias; ao final desse período, foram feitas as coletas de extrusa.

Antes e após a entrada dos animais na área, foram realizadas amostragens nas plantas de sabiá e no capim-braquiária, para determinação da composição química. Os animais foram recolhidos no final da tarde e soltos na manhã seguinte, para coleta da extrusa, quando as cânulas foram removidas e substituídas por bolsas coletoras, confeccionadas com lona impermeável contendo uma malha de náilon ao fundo para drenagem do excesso de saliva. Os animais foram colocados em pastejo por, aproximadamente, 40 minutos e, em seguida, foram contidos para coleta das amostras.

As amostras de extrusa foram divididas em duas subamostras (uma destinada à análise botânica e a outra às análises químicas), colocadas em sacos plásticos previamente identificados e armazenadas em freezer. Ao final da semana de amostragem, foi preparada uma amostra composta de cada animal. As amostras foram acondicionadas em gelo para que não houvesse mudanças na sua qualidade durante o transporte até o Laboratório de Nutrição Animal do Departamento de Zootecnia da UFRPE, onde foram preparadas conforme descrito anteriormente.

Foram realizadas observações da seletividade exercida pelo animal quando em pastejo no bosquede-sabiá. Os períodos de observação compreenderam os meses de junho e julho (período chuvoso) e outubro e novembro (período seco). Após a saída dos animais, foi utilizada uma escala de nota (1 a 5), adaptada de Lima (1995), para determinação do grau de desfolha de cada planta, identificando-se a preferência do animal (Tabela 1).

O método utilizado para análise da composição botânica do material de extrusa, foi o dos pontos microscópicos (Harker et al 1964), utilizando-se uma lupa binocular com objetiva de 16x, uma prancha de $88 \mathrm{~cm}$ de comprimento por 29,5 cm de largura, equipada com um trilho guia contendo 40 entalhes com distância de 1,0 cm entre eles, além de uma bandeja de alumínio medindo $45 \mathrm{~cm}$ de comprimento por $15 \mathrm{~cm}$ de largura. Foram amostrados $400 \mathrm{~g}$ de extrusa referente
Tabela 1 - Escala de pontuação de preferência de plantas pelos animais

Table 1 - Scale of punctuation of preference by plants

\begin{tabular}{lc}
\hline $\begin{array}{l}\text { Grau de desfolha } \\
\text { Degree of defoliation }\end{array}$ & $\begin{array}{c}\text { \% Preferência } \\
\text { \%Preference }\end{array}$ \\
\hline 0 & 0 \\
1 & 20 \\
2 & 40 \\
3 & 60 \\
4 & 80 \\
5 & 100 \\
\hline
\end{tabular}

Adaptada de Lima (1995).

Adapted from Lima (1995).

a cada período e espalhados na bandeja de alumínio, verificando-se, em seguida, a composição botânica da extrusa por meio dos pontos observados (400 pontos no total).

O delineamento utilizado foi o inteiramente casualizado e o modelo estatístico adotado nas análises dos dados, para avaliação da composição química das forragens e da composição botânica da extrusa, nos períodos chuvoso e seco, foi o seguinte:

$$
\mathrm{Y}_{\mathrm{ijk}}=\mu+\mathrm{P}_{\mathrm{i}}+\mathrm{E}_{\mathrm{j}}+(\mathrm{PE})_{\mathrm{ij}}+\varepsilon_{\mathrm{ijk}}
$$

em que: $\mathrm{Y}_{\mathrm{ijk}}=$ observação referente ao i-ésimo período, da j-ésima espécie, na k-ésima parcela; $\mu$ = média geral da variável; $\mathrm{P}_{\mathrm{i}}=$ efeito do i-ésimo período, com $\mathrm{i}$ = chuvoso e seco; $\mathrm{E}_{\mathrm{j}}$ = efeito da j-ésima "espécie", sendo j = sabiá com acúleo, sem acúleo, braquiária e extrusa, para composição química, ou efeito da jésima “espécie”, sendo j = sabiá, braquiária, falso anil e outras espécies, para composição botânica; (PE) = efeito da interação entre o i-ésimo período e o jésima espécie; e $\varepsilon_{\mathrm{ijk}}=$ erro aleatório associado a $\mathrm{Y}_{\mathrm{ijk}}$.

As médias da composição química das forragens e da extrusa e da composição botânica da extrusa, nos períodos chuvoso e seco, foram comparadas pelo teste Tukey a $5 \%$ de probabilidade.

\section{Resultados e Discussão}

Foi observado efeito significativo $(\mathrm{P}<0,05)$ do período sobre a composição da extrusa (Tabela 2).

No período chuvoso, com abundância de folhas de sabiá, as amostras de extrusa dos animais apresentaram maior $(\mathrm{P}<0,05)$ participação dessa forrageira (83,1\%), enquanto, no período seco, a participação do 
sabiá foi de apenas 12,3\%, em razão da senescência. Resultados semelhantes foram encontrados por Lima et al. (1987), que, procurando identificar a preferência dos animais por espécies arbustivas, arbóreas e herbáceas nativas e cultivadas nos períodos chuvoso e seco, verificaram que o mororó (Bauhinia cheillantha) e as gramíneas foram os componentes de maior participação no período chuvoso e que o mororó teve participação de 74,2 e 17,8\%, nos períodos chuvoso e seco, respectivamente.

O capim-braquiária foi a única forrageira que esteve disponível para os animais durante o período seco, o que resultou em participação de 69,7\% da dieta (Tabela 2). Outras espécies presentes no bosque também foram selecionadas e consumidas pelos animais, como falso anil, leucena, centrosema e ervas de pequeno porte, em decorrência da baixa disponibilidade de sabiá, independentemente do período de avaliação.

Uma das desvantagens da utilização de plantas forrageiras caducifólias, como sabiá, é a senescência das folhas no período seco, que traz implicações no desempenho dos animais, pela indisponibilidade, e, quando há disponibilidade, a qualidade pode ser uma limitação para atender determinadas categorias animais. Uma alternativa adotada por muitos criadores é a fenação desse material quando o valor nutricional é mais alto (período chuvoso) e existe disponibilidade de outras forragens para arraçoamento dos animais.

Tabela 2 - Composição botânica da extrusa de bovinos em pastejo em bosque-de-sabiá, nos períodos chuvoso e seco

Table 2 - Botanical composition of extrusa of cattle grazing sabiá pasture, in the rainy and dry periods

\begin{tabular}{lcc}
\hline & \multicolumn{2}{c}{ Período } \\
& \multicolumn{2}{c}{ Period } \\
\cline { 2 - 3 } & Chuvoso & $\begin{array}{c}\text { Seco } \\
\text { Dry }\end{array}$ \\
\hline Sabiá & $83,1 \mathrm{a}$ & $12,3 \mathrm{~b}$ \\
$\begin{array}{l}\text { Mimosa caesalpiniaefolia Benth. } \\
\text { Capim braquiária }\end{array}$ & $9,3 \mathrm{~b}$ & $69,7 \mathrm{a}$ \\
$\begin{array}{l}\text { Brachiaria decumbens Stapf. } \\
\text { Falso anil } \\
\text { Tephrosia noctiflora Boyer }\end{array}$ & $3,1 \mathrm{~b}$ & $11,5 \mathrm{a}$ \\
$\begin{array}{l}\text { Outras espécies } \\
\text { Other species } \\
\text { Coeficiente de variação (\%) } \\
\text { Coefficient of variation }\end{array}$ & $4,5 \mathrm{a}$ \\
\hline
\end{tabular}

Médias seguidas de mesma letra na mesma linha não diferem $(P>0,05)$ entre si pelo teste Tukey.

Means followed by the same letter in the same line are statistically similar $(P>.05)$, according to Tukey test.
Quanto à preferência dos animais pelas espécies de sabiá (Tabela 3), no período chuvoso, as plantas com acúleo corresponderam a 53,0\% e as sem acúleos, a $62,6 \%$ da dieta selecionada no mês de junho, enquanto, no mês de julho, a preferência foi de 63,4 e $73,8 \%$, respectivamente, para as plantas com e as sem acúleos. No período seco, as plantas com acúleo tiveram preferência de 3,4\% e as sem acúleos, de 0,8\% no mês de outubro, enquanto, no mês de novembro, a preferência foi de 0,6 e $0,4 \%$, respectivamente, para plantas com acúleos e as sem acúleos.

Quanto ao comportamento dos bovinos em pastejo, observou-se uma heterogeneidade nos locais de preferência dos animais, com tendência de os animais preferirem as plantas mais aos centro do bosque. Vale ressaltar que o número de plantas com acúleo foi menor, o que provavelmente influenciou a maior preferência por plantas sem acúleos.

Durante o período chuvoso, verificou-se preferência por plantas sem acúleo, o que provavelmente está associado ao maior acesso dos animais às partes dessas plantas e à maior facilidade de apreensão, ao passo que, no período seco, a preferência foi visível para o sabiá com acúleo. Lima (1995), trabalhando na mesma área experimental, observou maior preferência dos animais pelo sabiá sem acúleo.

No período chuvoso, não foram observadas diferenças significativas para quaisquer dos componentes nutricionais estudados entre os sabiás com e sem acúleo (Tabela 4). Os valores de PB dos sabiás com e sem acúleo (26,6 e 28,6\%, respectivamente) foram superiores aos encontrados por Vasconcelos (1997), Vieira et al. (1998) e Araújo Filho et al. (1998). O valor médio de PB (27,6\%), para ambas as espécies de sabiá, demonstra o potencial dessa leguminosa como

Tabela 3 - Porcentagem de preferência pelo sabiá com acúleo e pelo sabiá sem acúleo por bovinos, nos períodos chuvoso e seco

Table 3 - Preference (\%) by sabiá with and without thorn for cattle in the rainy and dry periods

\begin{tabular}{|c|c|c|c|c|}
\hline \multirow[b]{2}{*}{ Sabiá } & \multicolumn{2}{|c|}{$\begin{array}{c}\text { Período chuvoso } \\
\text { Rainy period }\end{array}$} & \multicolumn{2}{|c|}{$\begin{array}{l}\text { Período seco } \\
\text { Dry period }\end{array}$} \\
\hline & $\begin{array}{l}\text { Junho } \\
\text { June }\end{array}$ & $\begin{array}{l}\text { Julho } \\
\text { July }\end{array}$ & $\begin{array}{l}\text { Outubro } \\
\text { October }\end{array}$ & $\begin{array}{l}\text { Novembro } \\
\text { November }\end{array}$ \\
\hline $\begin{array}{l}\text { Com acúleos } \\
\text { With thorn }\end{array}$ & 53,00 & 63,40 & 3,40 & 0,60 \\
\hline $\begin{array}{l}\text { Sem acúleos } \\
\text { Without thorn }\end{array}$ & 62,60 & 73,80 & 0,80 & 0,40 \\
\hline
\end{tabular}


Tabela 4 - Composição químico-bromatológica dos sabiás com e sem acúleo, do capim-braquiária e da extrusa de bovinos em pastejo em bosque-de-sabiá, conforme o período de amostragem

Table 4 - Chemical composition of sabiá with and without thorn, signalgrass and extrusa of cattle grazing sabiá pasture, according to sampling period

\begin{tabular}{|c|c|c|c|c|c|c|c|c|c|}
\hline \multirow[t]{2}{*}{$\begin{array}{l}\text { Nutriente } \\
\text { Nutrient }\end{array}$} & \multicolumn{2}{|c|}{$\begin{array}{l}\text { Sabiá com acúleo } \\
\text { Sabiá with thorn }\end{array}$} & \multicolumn{2}{|c|}{$\begin{array}{l}\text { Sabiá sem acúleo } \\
\text { Sabiá without thorn }\end{array}$} & \multicolumn{2}{|c|}{$\begin{array}{l}\text { Braquiária } \\
\text { Signalgrass }\end{array}$} & \multicolumn{2}{|c|}{$\begin{array}{l}\text { Extrusa } \\
\text { Extrusa }\end{array}$} & \multirow[t]{2}{*}{ CV (\%) } \\
\hline & $\begin{array}{c}\text { Chuvoso } \\
\text { Rainy }\end{array}$ & $\begin{array}{l}\text { Seco } \\
\text { Dry }\end{array}$ & $\begin{array}{c}\text { Chuvoso } \\
\text { Rainy }\end{array}$ & $\begin{array}{l}\text { Seco } \\
\text { Dry }\end{array}$ & $\begin{array}{c}\text { Chuvoso } \\
\text { Rainy }\end{array}$ & $\begin{array}{c}\text { Seco } \\
\text { Dry }\end{array}$ & $\begin{array}{c}\text { Chuvoso } \\
\text { Rainy }\end{array}$ & $\begin{array}{l}\text { Seco } \\
\text { Dry }\end{array}$ & \\
\hline $\begin{array}{l}\text { MS (\%) } \\
D M(\%)\end{array}$ & $25,8 a B$ & $42,8 \mathrm{~b} \mathrm{~A}$ & $27,1 \mathrm{aB}$ & $42,0 \mathrm{~b} \mathrm{~A}$ & 18,За В & $57,5 \mathrm{a} A$ & $19,7 \mathrm{a} A$ & 20,39с A & 13,9 \\
\hline $\begin{array}{l}\mathrm{PB}(\% \mathrm{MS}) \\
C P(\% \mathrm{DM})\end{array}$ & 26,6a A & $18,8 \mathrm{a} B$ & 28,6a A & 19,8a B & $14,0 \mathrm{~b} \mathrm{~A}$ & $6,9 \mathrm{~b}$ B & $25,9 \mathrm{a} A$ & $12,4 \mathrm{bB}$ & 9,5 \\
\hline $\begin{array}{l}\text { PIDA (\% PB) } \\
I P A D(\% C P)\end{array}$ & $12,6 \mathrm{~b} \mathrm{~A}$ & 9,8ab A & $11,6 \mathrm{~b} \mathrm{~A}$ & $10,4 \mathrm{a} A$ & $3,4 \mathrm{c} \mathrm{A}$ & $2,3 \mathrm{c} \mathrm{A}$ & $17,6 \mathrm{a} A$ & 5,5bc B & 11,4 \\
\hline $\begin{array}{l}\text { EE (\% MS) } \\
E E(\% D M)\end{array}$ & 5,1ab A & 5,5a A & 5,4a A & 5,4a A & $2,2 \mathrm{c} \mathrm{A}$ & $1,2 \mathrm{c} \mathrm{A}$ & 3,7b A & $2,8 \mathrm{~b} \mathrm{~A}$ & 9,9 \\
\hline $\begin{array}{l}\text { FDN (\% MS) } \\
N D F(\% D M)\end{array}$ & 46,1b A & $38,7 \mathrm{~b} A$ & $42,7 \mathrm{~b} \mathrm{~A}$ & $39,4 \mathrm{~b}$ A & $66,5 \mathrm{a} A$ & $74,5 \mathrm{a} A$ & 64,3a A & $64,8 \mathrm{a} A$ & 9,8 \\
\hline $\begin{array}{l}\text { FDA (\% MS) } \\
A D F(\% D M)\end{array}$ & 26,6 bc A & $22,5 b \mathrm{~A}$ & 25,0 c A & $21,1 \mathrm{~b}$ A & 34,0b B & 42,3a A & $44,1 \mathrm{a} A$ & $40,2 \mathrm{a} A$ & 8,7 \\
\hline $\begin{array}{l}\text { Hemicelulose (\% MS) } \\
\text { Hemicell (\% DM) }\end{array}$ & ) $19,5 \mathrm{~b} \mathrm{~A}$ & $16,2 \mathrm{~b} \mathrm{~A}$ & $17,7 \mathrm{~b} \mathrm{~A}$ & $18,3 \mathrm{~b} \mathrm{~A}$ & $32,5 \mathrm{a} A$ & 32,3a A & $20,2 \mathrm{~b} \mathrm{~A}$ & 24,7ab A & 16,7 \\
\hline $\begin{array}{l}\text { Celulose (\% MS) } \\
\text { Cellulose (\% DM) }\end{array}$ & $14,2 \mathrm{~b} \mathrm{~A}$ & $13,6 \mathrm{~b} \mathrm{~A}$ & $14,4 \mathrm{~b} \mathrm{~A}$ & $12,1 \mathrm{~b} \mathrm{~A}$ & $23,4 a$ B & 29,3а A & 20,7 a B & 26,3a A & 11,4 \\
\hline $\begin{array}{l}\text { Lignina (\% MS) } \\
\text { Lignin (\% DM) }\end{array}$ & $11,0 \mathrm{~b} \mathrm{~A}$ & 8,6a A & $10,7 \mathrm{~b} \mathrm{~A}$ & $9,2 \mathrm{a} A$ & $8,2 \mathrm{~b} \mathrm{~A}$ & 6,9a A & $22,4 \mathrm{a} A$ & 10,1aB & 10,1 \\
\hline $\begin{array}{l}\text { Energia bruta } \\
\text { (kcal/kg MS) } \\
\text { Crude energy (kcal/kg L }\end{array}$ & $\begin{array}{l}\text { 5197a A } \\
\text { DM) }\end{array}$ & 5143a A & 5281a A & 5132a A & $4741 \mathrm{~b} \mathrm{~A}$ & 4632b A & 5221a A & 4679b B & 5,1 \\
\hline
\end{tabular}

Médias na linha e dentro de cada período (chuvoso ou seco), seguidas de mesma letra minúscula, não diferem ( $P>0,05)$ pelo teste Tukey. Médias nas linhas e entre períodos (chuvoso ou seco) para as mesmas forragens, seguidas de mesma letra maiúscula, não diferem $(P>0,05)$ pelo teste Tukey.

Means in a row and within periods (rainy or dry), followed by the same small letter, do not differ ( $P>0.05)$ by Tukey test.

Means in a row and within periods (rainy or dry), for the same forages, followed by the same capital letter, do not differ $(P>0.05)$ by Tukey test.

forrageira. Os teores de proteína insolúvel em detergente ácido (PIDA) foram semelhantes aos relatados por Vasconcelos (1997) e se assemelham aos de outras forrageiras. Os teores de FDN, FDA e lignina, no período chuvoso, foram inferiores aos observados por Vasconcelos (1997), que encontrou, respectivamente, valores de 52,2; 31,0 e 11,6\%.

Comparando os dados de composiçãobromatológica da extrusa com os dos sabiás com e sem acúleo, ainda no período chuvoso, observou-se que, na extrusa, os teores da fração fibra (FDN, FDA, celulose e lignina) foram maiores $(\mathrm{P}<0,05)$. Este resultado evidencia que a coleta manual provavelmente superestimou a qualidade do alimento ingerido. As porcentagens de PB da extrusa e do sabiá no período chuvoso foram semelhantes $(\mathrm{P}>0,05)$, refletindo a participação de sabiá na extrusa, que apresentou $25,9 \%$ de PB.

A maior participação da fibra na extrusa está associada ao hábito de apreensão de alimentos dos bovinos, em grandes bocados e à baixa seletividade, uma vez que os teores de FDN e FDA verificados no material coletado (sabiá) podem ser considerados relativamente baixos para bovinos em pastejo, confirmando os resultados obtidos por Detmann et al. (1999), que demonstraram que a coleta manual superestimou os valores nutricionais quando comparados à extrusa.

A porcentagem de MS da extrusa no período seco foi inferior $(\mathrm{P}<0,05)$ às porcentagens de MS das forragens consumidas, o que se deve, provavelmente, à presença da saliva na extrusa, umedecendo a ingesta. A ação da saliva, inclusive, tornou sem diferença $(\mathrm{P}>0,005)$ a porcentagem de MS da extrusa entre os períodos chuvoso e seco.

No período seco, da mesma forma que no período chuvoso, não houve diferença $(\mathrm{P}>0,05)$ entre os sabiás com e sem acúleo para quaisquer dos componentes nutricionais avaliados. Todavia, diferentemente do que ocorreu no período chuvoso, a extrusa do período seco 
apresentou menor $(\mathrm{P}<0,05)$ teor de $\mathrm{PB}(12,4 \%)$ que o material coletado, com valores de 18,9 e $19,8 \%$ de PB para os sabiás com e sem acúleo, respectivamente. Essa resposta está associada à participação do capim-braquiária na dieta dos animais (Tabela 2), considerando-se que o bosque-de-sabiá apresentava-se em estado de senescência, contribuindo, portanto, com menor quantidade de proteína na dieta. As demais diferenças entre a composição química da extrusa com o sabiá e o capimbraquiária estão associadas à maior participação do capim-braquiária na composição da dieta no período seco.

A composição química das forragens e da extrusa no período seco indica que, se comparados aos do períodos chuvoso, os valores de MS dos sabiás com e sem acúleo (25,8 e 27,1\% vs 42,8 e 42,0\%) foram maiores $(\mathrm{P}<0,05)$ e os de $\mathrm{PB}(26,6$ e $28,6 \%$ vs 18,8 e $19,8 \%)$ menores $(\mathrm{P}<0,05)$. Apesar disso, o valor médio de 19,3\% de PB para sabiá no período seco pode ser considerado alto e foi ligeiramente superior ao encontrado por Vasconcelos (1997) para essa forrageira no período chuvoso. Da mesma forma, o capim-braquiária apresentou metade do valor $(\mathrm{P}<0,05)$ de PB no período seco em relação ao chuvoso $(14,0$ vs $6,9 \%$ ), refletindo diretamente no valor de $12,4 \%$ da proteína da extrusa no período seco, que representou a metade $(\mathrm{P}<0,05)$ da proteína presente na extrusa do período chuvoso (25,9\%).

Em razão da menor participação de sabiá no período seco, o valor energético da extrusa foi menor $(\mathrm{P}<0,05)$ que no período chuvoso. Esse maior valor energético de sabiá está associado ao maior teor $(\mathrm{P}<0,05)$ de extrato etéreo presente nessa forrageira tanto no período seco quanto no chuvoso, em relação ao capim-braquiária. O valor de extrato etéreo obtido neste trabalho $(5,1 \%)$ é foi semelhante ao encontrado

Tabela 5 - Composição mineral dos sabiás com e sem acúleo, do capim-braquiária e da extrusa de bovinos em pastejo em bosque de sabiá, nos períodos chuvoso e seco

Table 5 - Mineral composition of the sabiá with thorn, sabiá without thorn, signal grass and extrusa of cattle grazing sabiá pasture, in the rainy and dry periods

\begin{tabular}{|c|c|c|c|c|c|c|c|c|c|}
\hline \multirow[t]{2}{*}{$\begin{array}{l}\text { Nutriente } \\
\text { Nutrient }\end{array}$} & \multicolumn{2}{|c|}{$\begin{array}{l}\text { Sabiá com acúleo } \\
\text { Sabiá with thorn }\end{array}$} & \multicolumn{2}{|c|}{$\begin{array}{l}\text { Sabiá sem acúleo } \\
\text { Sabiá without thorn }\end{array}$} & \multicolumn{2}{|c|}{$\begin{array}{l}\text { Braquiária } \\
\text { Signalgrass }\end{array}$} & \multicolumn{2}{|c|}{$\begin{array}{l}\text { Extrusa } \\
\text { Extrusa }\end{array}$} & \multirow[t]{2}{*}{ CV (\%) } \\
\hline & $\begin{array}{l}\text { Chuvoso } \\
\text { Rainy }\end{array}$ & $\begin{array}{l}\text { Seco } \\
\text { Dry }\end{array}$ & $\begin{array}{l}\text { Chuvoso } \\
\text { Rainy }\end{array}$ & $\begin{array}{l}\text { Seco } \\
\text { Dry }\end{array}$ & $\begin{array}{c}\text { Chuvoso } \\
\text { Rainy }\end{array}$ & $\begin{array}{l}\text { Seco } \\
\text { Dry }\end{array}$ & $\begin{array}{c}\text { Chuvoso } \\
\text { Rainy }\end{array}$ & $\begin{array}{l}\text { Seco } \\
\text { Dry }\end{array}$ & \\
\hline $\begin{array}{l}\text { Matéria mineral (\% MS) } \\
\text { Mineral matter (DM\%) }\end{array}$ & 5,22a A & 5,63a A & 5,30a A & 5,98a A & 7,10a A & 5,61a A & 7,55a A & 8,13a A & 16,8 \\
\hline $\begin{array}{l}\text { Cálcio (\% MS) } \\
\text { Calcium (DM\%) }\end{array}$ & $1,49 \mathrm{a} A$ & 1,02a A & 0,99a A & 1,48a A & 0,90a A & 1,38a A & 2,04a A & 1,12a A & 28,3 \\
\hline $\begin{array}{l}\text { Fósforo (\% MS) } \\
\text { Phosphorus (\% DM) }\end{array}$ & $0,20 \mathrm{a} A$ & 0,14a B & $0,24 \mathrm{a} A$ & 0,16a B & $0,25 \mathrm{a} A$ & 0,10a B & 0,28a A & 0,24a A & 13,4 \\
\hline $\begin{array}{l}\text { Potássio (\% MS) } \\
\text { Potassium (DM\%) }\end{array}$ & 1,72ab A & 1,61a A & 1,54ab A & 1,66a A & 2,16a A & 1,28a B & 1,17b A & 1,42a A & 18,6 \\
\hline $\begin{array}{l}\text { Sódio (\% MS) } \\
\text { Sodium (DM\%) }\end{array}$ & $0,15 b \mathrm{~A}$ & $0,25 b \mathrm{~A}$ & 0,10b A & 0,30b A & $0,20 \mathrm{~b} \mathrm{~A}$ & 0,50b A & 0,74a B & 0,87a A & 27,1 \\
\hline $\begin{array}{l}\text { Magnésio (\% MS) } \\
\text { Magnesium (DM\%) }\end{array}$ & $0,55 \mathrm{a} A$ & 0,44a A & 0,71a A & 0,30a A & $0,34 \mathrm{a} A$ & 0,20a A & 1,12a A & 0,13a A & 65,4 \\
\hline $\begin{array}{l}\text { Enxofre (\% MS) } \\
\text { Sulfur (DM\%) }\end{array}$ & $0,15 b \mathrm{~A}$ & 0,12b A & $0,15 b \mathrm{~A}$ & $0,12 \mathrm{~b} \mathrm{~A}$ & $0,12 \mathrm{~b} \mathrm{~A}$ & 0,11b A & 0,43a A & 0,53a A & 13,9 \\
\hline $\begin{array}{l}\text { Ferro (mg/kg MS) } \\
\text { Iron ( } \mathrm{mg} / \mathrm{kg} D M)\end{array}$ & $117,4 \mathrm{a} A$ & 160,9a A & $133,2 \mathrm{a} A$ & $216,0 \mathrm{a} A$ & 156,9a A & $225,6 a \mathrm{~A}$ & 163,5a В & 303,3а A & 29,0 \\
\hline $\begin{array}{l}\text { Cobre (mg/kg MS) } \\
\text { Copper (mg/kg DM) }\end{array}$ & 20,67 a A & $17,4 \mathrm{a} A$ & $19,94 \mathrm{a} A$ & 21,3a A & $25,46 \mathrm{a} A$ & $14,2 \mathrm{a} A$ & $20,88 \mathrm{a} A$ & 21,8a A & 16,3 \\
\hline $\begin{array}{l}\text { Zinco (mg/kg MS) } \\
\text { Zinc (mg/kg DM) }\end{array}$ & 48,66a A & $38,2 \mathrm{a} B$ & 52,71a A & 38,1a A & 42,70a A & 40,6a A & 41,79a A & 46,7a A & 8,2 \\
\hline $\begin{array}{l}\text { Manganês (mg/kg MS) } \\
\text { Manganese (mg/kg DM) }\end{array}$ & 74,61a A & $84,7 \mathrm{ab}$ A & 67,36a A & 93,1ab A & $44,52 \mathrm{a} A$ & 57,5b A & 81,90a A & $100,4 \mathrm{a} A$ & 20,1 \\
\hline
\end{tabular}

Médias na linha e dentro de cada período (chuvoso ou seco), seguidas de mesma letra minúscula, não diferem $(P>0,05)$ pelo teste Tukey. Médias nas linhas e entre períodos (chuvoso ou seco) para as mesmas forragens, seguidas de mesma letra maiúscula, não diferem $(P>0,05)$ pelo teste Tukey.

Means in a row and within periods (rainy or dry), followed by the same small letter, do not differ ( $P>0.05)$ by Tukey test.

Means in a row and within periods (rainy or dry), for the same forages, followed by the same capital letter, do not differ $(P>0.05)$ by Tukey test. 
por Vasconcelos (1997), no período chuvoso (4,9\%), mas, no período seco (5,4\%), foi bem inferior aos $10,2 \%$ verificados pelo mesmo autor.

Observou-se que os sabiás com e sem acúleo não apresentaram diferenças em nenhum dos minerais determinados, tanto no período seco quanto no período chuvoso, mas houve diferença $(\mathrm{P}<0,05)$ no teor de fósforo para ambas as espécies entre os períodos secos e chuvoso (Tabela 5). O sabiá apresentou queda menos acentuada do período chuvoso para o seco que o capim-braquiária, cujo valor ficou em $0,10 \%$ no período seco. Isso tem implicações no atendimento das exigências de fósforo para ruminantes em produção.

De modo geral, o sabiá apresentou bons valores dos principais minerais, sem muitas diferenças em relação a outras leguminosas.

Quanto aos minerais avaliados na extrusa, verificou-se que os teores de sódio foram superiores ao das forragens estudadas $(\mathrm{P}<0,05)$, tanto no período chuvoso quanto no período seco. Isso está associado à contaminação pela saliva, que é rica em sódio. Também foi observada diferença $(\mathrm{P}<0,05)$ no teor de sódio da extrusa entre os períodos chuvoso $(0,74 \%)$ e seco $(0,87 \%)$, que pode estar relacionada à maior quantidade de matéria seca nas forragens durante o período seco (Tabela 4), conduzindo a maior produção de saliva e, conseqüentemente, maior teor de sódio.

De modo semelhante ao sódio, o enxofre esteve em maior porcentagem na extrusa, tanto no período seco quanto no chuvoso $(\mathrm{P}<0,05)$, o que está associado à alguma contaminação microbiana nas amostras de extrusa.

\section{Conclusões}

A composição bromatológica do sabiá apresentou diferenças de pequena magnitudes entre plantas com e sem acúleo, sendo o período do ano o fator mais determinante dessas diferenças.

O período do ano influenciou a composição botânica da extrusa, sendo o sabiá mais selecionado no período chuvoso e o capim-braquiária no período seco.

\section{Literatura Citada}

ARAÚJO FILHO, J.A.; CARVALHO, F.C.; GADELHA, J.A. et al. Fenologia e valor nutritivo de espécies lenhosas caducifólias da caatinga. In: REUNIÃO ANUAL DA SOCIEDADE BRASILEIRA DE ZOOTECNIA, 35.,
1998, Botucatu. Anais... Botucatu: Sociedade Brasileira de Zootecnia, 1998. p.360-362.

BARBOSA, H.P. Tabela de composição de alimentos do estado da Paraíba, “setor agropecuário”. Areia: Universidade Federal da Paraíba, 1997. 163p.

BEZERRA NETO, E.; ANDRADE, A.G.; BARRETO, L.P. Análise química de tecidos e produtos vegetais. Recife: Universidade Federal Rural do Pernambuco, 1994. 99p.

BISHOP, J.P.; FROSETH, J.A. Improved techniques in esophageal fistulization of sheep. American Journal Veterinary Research, v.31, n.8, p.1505-1507, 1970.

CARVALHO, J.H.; MAIA, C.M.N.A.; AMORIM, G.C. Seleção de sabiá (Mimosa caesalpiniifolia Benth.), leguminosa madeireira e forrageira, para a obtenção de plantas sem acúleos. Mossoró: ESAM, 1990. 9p. (ESAM Coleção Manoroense, 782, Série B).

DETMANN, E.; PAULINO, M.F.; ZERVOUDAKIS, J.T. et al. Avaliação qualitativa de dois métodos de amostragens de dieta em pastagens de capim-braquiária (Brachiaria decumbens Stapf). In: REUNIÃO DA SOCIEDADE BRASILEIRA DE ZOOTECNIA, 36., 1999, Porto Alegre. Anais... São Paulo: Sociedade Brasileira de Zootecnia/Gmosis, [1999]. CD-ROM. Forragicultura. FOR-018.

HARKER, K.W.; TORELL, D.T.; VAN DYNE, G.M. Botanical examination of forage from esofageal fistules in cattle. Journal of Animal Science, v.34, n.3, p.465-469. 1964.

JACOMINE, P.K.T. Levantamento exploratório - reconhecimento de solos do Estado de Pernambuco, descrição de perfis de solos e análises. Recife: MA - DNPEA/SUDENE/ DRN, 1972. v.1 (Boletim Técnico, 26).

LIMA, I.C.A.R. Estudo da sabiazeiro (Mimosa caesalpiinifolia Benth) para seleção de ausência de acúleos visando pastejo. Recife: Universidade Federal Rural do Pernambuco, 1995. 135p. Dissertação (Mestrado em Botânica) - Universidade Federal Rural do Pernambuco, 1995.

LIMA.M.A.; FERNANDES, A.P.M.; SILVA M.A. et al. Avaliação de forrageiras nativas e cultivadas em áreas de Caatinga no Sertão de Pernambuco. Revista Brasileira de Zootecnia, v.16, n.6, p.517-531, 1987.

MALAVOLTA, E.; VITTI, G.C.; OLIVEIRA, S.A. Avaliação do estado nutricional das plantas: princípios e aplicações. Piracicaba: POTAFOS, 1989. 201p.

SILVA, D.J.; QUEIROZ, A.C. Análise de alimentos: métodos químicos e biológicos. 3.ed. Viçosa, MG: Universidade Federal de Viçosa, 2002. 235p.

SILVA, C.M.M.S.; OLIVEIRA, M.C.; SOARES, J.G.G. Avaliação de forrageiras nativas e exóticas para a região semiárida do Nordeste. Petrolina: EMBRAPA - CPATSA, 1984. p.28 (Documentos, 27).

VASCONCELOS, V.R. Caracterização química e degradação de forrageiras do semi-árido brasileiro no rúmen de caprinos. Jaboticabal: Universidade Estadual Paulista, 1997. Tese (Doutorado em Zootecnia) - Universidade Estadual Paulista, 1997. 132p.

VIEIRA, E.L.; SILVA, A.M.A.; COSTA, R.G. et al. Valor nutritivo do feno de espécies lenhosas ca Caatinga. In: REUNIÃO ANUAL DA SOCIEDADE BRASILEIRA DE ZOOTECNIA, 35., 1998, Botucatu. Anais... Botucatu: Sociedade Brasileira de Zootecnia, p.227-229. 1998.

Recebido em: 14/10/04 Aceito em: 08/06/05 